\title{
Molecular epidemiology of JC polyomavirus in HIV-infected patients and healthy individuals from Iran
}

\author{
Manoochehr Makvandi ${ }^{1} \cdot$ Hayat Mombeini ${ }^{2} \cdot$ Somayeh Biparva Haghighi ${ }^{3} \cdot$ Maryam Dastoorpoor $^{4}$. \\ Nastaran Khodadad ${ }^{1} \cdot$ Mohammad Karimi Babaahmadi $^{5} \cdot$ Maryam Tabasi $^{1} \cdot$ Roya Pirmoradi $^{1}$
}

Received: 6 April 2019 / Accepted: 2 July 2019/Published online: 30 July 2019

(C) Sociedade Brasileira de Microbiologia 2019

\begin{abstract}
JC polyomavirus (JCPyV) is the causative agent for progressive multifocal leukoencephalopathy (PML) in immunocompromised patients. More than $40 \%$ of healthy population excretes JCPyV particles in their urine. As JCPyV is ubiquitous in human, the definition of genotype distribution can help trace population migration. In this study, to define the frequency of JCPyV in southwest of Iran, urine samples of 161 volunteers including 80 healthy individuals and $81 \mathrm{HIV}$-infected patients were collected. PCR assays and sequence analysis were performed using JCPyV-specific primers designed against VP1 coding region. JCPyV DNA was detected in 65 out of 81 urine samples $(80.2 \%)$ of HIV-infected, and in 43 out of 80 urine samples (53.8\%) of healthy individuals $(P=0.001)$. The shedding of JCPyV among HIV-infected patients revealed an age-related pattern while such relationship was not observed in healthy individuals group. The most common genotype found in this region was genotype $3 \mathrm{~A}$ (80.8\%), followed by genotype 2D (11.5\%), 4 (3.8\%), and 7 (3.8\%). The frequency of JCPyV in the urine of HIV-infected patients was found significantly higher than in the healthy individuals $(P=0.001)$.
\end{abstract}

Keywords JC polyomavirus $\cdot$ Polyomavirus $\cdot$ Genotype $\cdot$ VP1 gene $\cdot$ Polymerase chain reaction

\section{Introduction}

JC polyomavirus is a member of the Polyomaviridae family [1]. They are small, non-enveloped DNA viruses with a 5.1 kilo base pairs (kbp) supercoiled, double-stranded DNA genome [2]. The genome has two main regions known as early

Responsible Editor: Giliane Souza Trindade

Roya Pirmoradi

royapirmoradi@yahoo.com

Manoochehr Makvandi

manoochehrmakvandi299@gmail.com

Hayat Mombeini

mombeini-ha@ajums.ac.ir

Somayeh Biparva Haghighi

biparva_somayeh@yahoo.com

Maryam Dastoorpoor

m.dastoorpour@yahoo.com

Nastaran Khodadad

lili_virus2011@yahoo.com

Mohammad Karimi Babaahmadi

m.karimi444@gmail.com and late genes which are separated by a non-bonding control region (NCCR) containing the origin of replication (Ori) [3]. The early gene encodes large $\mathrm{T}$ antigen and small $\mathrm{t}$ antigen, which contribute to the viral replication [4]. Large $\mathrm{T}$ antigen appears to be involved in tumor genesis because of its ability in cell transformation in vivo and in vitro [5]. All Polyomaviruses

Maryam Tabasi

maryam.tabasi@yahoo.com

1 Department of Virology, Faculty of Medicine, Ahvaz Jundishapur University of Medical Sciences, Ahvaz, Iran

2 Department of Urology, Golestan Hospital, Ahvaz Jundishapur University of Medical Sciences, Ahvaz, Iran

3 Department of General Courses, School of Medicine, Ahvaz Jundishapur University of Medical Sciences, Ahvaz, Iran

4 Department of Epidemiology and Biostatistics, Menopause Andropause Research Center, Ahvaz Jundishapur University of Medical Sciences, Ahvaz, Iran

5 Department of Medical Biotechnology, Faculty of Advanced Medical Sciences, Tabriz University of Medical Sciences, Tabriz, Iran 
have also three structural proteins termed VP1, VP2, and VP3 which are encoded by late genes as well as Agno protein [6].

$\mathrm{JCPyV}$ is endemic so most human populations are infected with the virus during childhood [7]. The frequency of JCPyV in adult population is approximately $70 \%$, although the virus is silently shed in the urine of $\sim 40 \%$ of adults $[4,5]$.

There are two different classifications of JCPyV genotyping. The early genotyping was designed by Yogo et al. based on restriction fragment length polymorphism (RFLP) and later confirmed by V-T intergenic region dividing JCPyV in genotypes based on an alphabetical order (A, B, C, and D) [8,9]. The second system of JCPyV classification was primarily based on the analyses of the sequence variation of the $\mathrm{V}$-T intergenic region. Later, an upstream major capsid protein (VP1) gene fragment was used to classify different genotypes [10]. Using this method presented by Agostini et al., more than 7 genotypes numbered 1 to 8 and several subtypes were identified [6, 10, 11]. All JCPyV isolated worldwide belong to a unique serotype but there is a number of JCPyV genotypes that are used for tracing human migration in the world $[6,12,13]$. Type 1 (type A subtype EU) is prevalent in Europe and the USA, while type 2 (type B subtype B1 \& MY) and type 7 (type B subtype SC) are Asian types. Type 3 (type B subtype Af2) and 6 (type C subtype Af1) are found in Africa and type 4 is associated with type 1 which has been found in the USA and Europe [14-16]. JCPyV genotype 5 is a recombinant type between type $2 \mathrm{~b}$ and type 6 [16]. Type 8 is found in the Western Pacific and Papua New Guinea populations [17]. Type 2 is classified into 4 subtypes. The main subtypes in the northeastern part of Asia are $2 a$ and $2 \mathrm{c}$ while the dominant subtype is $2 \mathrm{~b}$ in west of Asia. Subtypes $2 \mathrm{~d}$ and $2 \mathrm{e}$ are prevalent in India and Guam, respectively [15].

Latent infection is induced by the virus in the kidney, lymphocyte, spleen, and bone marrow [18]. JCPyV reactivation under immunosuppressive condition causes deadly demyelinating disease of the central nervous system known as progressive multifocal leukoencephalopathy (PML) as well as various neurological diseases including granule cell neuronopathy, meningitis, and JCPyV encephalopathy [19, 20]. PML was a rare disease before AIDS pandemic. An extreme rise in the PML incidence occurred in the world after the HIV outbreak in the early 1980s [21-23]. Recently, the number of the HIVinfected people with PML disorder has decreased because of the extensive use of combined antiretroviral therapies. Currently, PML has been observed in the patients with autoimmune disorders who take immunomodulatory medication such as natalizumab, rituximab, and efalizumab [20]. Yet, HIV infection still remains as the most frequent immunodeficiency setting concerning PML [24]. Previous studies indicated a difference in JCPyV excreted in the urine of HIV-infected patients compared with healthy individuals, albeit the difference was not significant. Similarly, the distribution of genotypes between these two groups was not different [13, 25 ]. Among JCPyV genotypes, type $2 b$ has proved to be related with the high-risk PML disorder in immunodeficient patients [7]. Hence, this project was carried out to detect JCPyV prevalence and the genotype distribution in HIVinfected patients in comparison with healthy individuals as a molecular-based epidemiological survey in Ahvaz city, Iran.

\section{Materials and methods}

\section{Patients and collection of clinical samples}

Eighty-one samples were obtained from HIV-infected patients when they referred to the High Risk Behavior Guidance Center in Ahvaz for checking their CD4 count and taking medicines. Inclusion criteria involved (a) HIV-positive ELISA and Western blot serology, (b) CD4 cell count $<600 \times 10^{6}$ cell/1, (c) receiving HAART regimen for at least 3 months, (d) no sign of active malignancy or other infectious diseases, and (e) no pregnant female. Any sign of other active infectious diseases or malignancy caused exclusion from the group. Also, 80 samples were collected from healthy individuals who had referred to diagnostic laboratories for checkup, without any malignancy and immunosuppression conditions. Fresh urine samples were sent immediately to the laboratory of virology department and stored at $-70^{\circ} \mathrm{C}$.

\section{DNA extraction and PCR amplification}

Fifteen milliliters of the urine was centrifuged at $3500 \mathrm{rpm}$ for $15 \mathrm{~min}$. The cell pellet remained suspended in phosphatebuffered saline (PBS) by vortexing, recentrifuged, with the supernatant discarded. Viral DNA was then extracted using QIAamp Viral DNA isolation micro kit (Qiagen Inc., Germany) according to the manufacturer's protocol, and then stored at $-20^{\circ} \mathrm{C}$ until the next phase. Two primer sets were designed using the Oligo version 7 software for amplifying 649 and $768 \mathrm{bp}$ fragments in order to yield the entire VP1 coding region for JCPyV genotyping. The first and the second primer pairs are presented in Table 1.

Finally, PCR amplification was run with a total of $50 \mu \mathrm{L}$ consisting of $25 \mu \mathrm{L}$ PCR Master Mix (Amplicon), $2 \mu \mathrm{L}$ $(1 \mu \mathrm{M})$ each of FW and RV primers, $5 \mu \mathrm{L}$ extracted DNA, and $16 \mu \mathrm{L}$ injection grade water. The PCR reaction mixture was subjected to thermocycler (Peqlab, Germany) with the following thermal program: initial activation step at $94{ }^{\circ} \mathrm{C} /$ $5 \mathrm{~min}, 35$ cycles of $95{ }^{\circ} \mathrm{C} / 45 \mathrm{~s}, 50{ }^{\circ} \mathrm{C} / 45 \mathrm{~s}, 72{ }^{\circ} \mathrm{C} / 45 \mathrm{~s}$, and a final extension at $72{ }^{\circ} \mathrm{C}$ for $10 \mathrm{~min}$. All samples along with negative control (previously known as negative sample) and positive control (previously known as positive sample) were amplified. The PCR products were detected by 
Table 1 The sequences of JCPyV primers for PCR and cycle sequencing

\begin{tabular}{lllc}
\hline Primer & Sequence $\left(5^{\prime}-3^{\prime}\right)$ & Position & Amplicon size \\
\hline F3J & ACAGCATTCAAGAAGTTACCCA & $1280-1302$ & 649 \\
R3J & CCCCTGTAATTCTAAAGCCTCC & $1928-1906$ & \\
F4J & ACTCTAATGGTCAAGCAACTC & $1824-1844$ & 768 \\
R4J & GCAACTGTAAAGTAAAGCTGG & $2591-2571$ & \\
\hline
\end{tabular}

electrophoresis on $1.5 \%$ agarose gel, where the size of the amplified products was anticipated by the migration pattern of a 100-bp DNA ladder.

\section{Sequencing and phylogenetic analysis}

Positive results of PCR amplification were sequenced in both the forward and reverse direction with the same primer sets used for PCR amplification. The DNA sequencing was conducted on an ABI 3730XL DNA Analyzer (Bioneer, South Korea) via BigDye ${ }^{\mathrm{TM}}$ cyclic Sequencing. SnapGene sequence alignment editor version 3.2.1 was used to align sequences with consensus sequences obtained. The MEGA7 software was utilized for phylogenetic analysis. The multiple sequences alignment of retrieved sequences from GenBank and the sequences of this research were obtained by CLUSTALW. Distances were evaluated via Tamura Nei-model method. The bootstrap maximum likelihood method with 1000 replicates was performed to determine the evolutionary distances.

\section{GenBank accession numbers}

The sequences reported in this research were deposited in the GenBank database under the accession numbers: MH454250, MH602988, MH643768, MH643769, МH643770, MH643771, MH643772, MH667311, MH667312, MH667313, MH667314, MH688160, MH688161, MH688162, MH688163, MH688164, MH688165, MH688166, MK028301, MK028302, MK028303, MH725628, MH725629, MH725630, MH725631, and MH725632.

\section{Statistical analyses}

In this study, as an essential part of biometric analysis, descriptive statistics was run to describe mean, standard deviation, and frequency. Also, in the inferential statistics section, nonparametric chi-square and fisher exact tests were conducted to compare the frequency of qualitative variables based on the group variable (HIV-infected patients and healthy individuals). The analyses were performed using SPSS 22 software and the significance level was less than 0.05 .

\section{Results}

\section{JCPyV DNA excretion}

This study was conducted on urine samples of HIVinfected patients (81 samples) and healthy individuals (80 samples) to acquire the prevalence and genotyping of JCPyV in these two groups in southwest of Iran. HIVinfected patients included 23 females and 58 males ranging from 8 to 68 years of age with an average age of 39.8 . On the other hand, the healthy group consisted of 50 females and 30 males with the age range of 2 to 71 years. The average age of the subjects in this group was 41.1 years. The results of PCR assay indicated that in HIV-infected group, 65/81 patients $(80.2 \%)$ had shed JCPyV in their urine. Among healthy individuals, viral DNA was detected in 43 out of $80(53.8 \%)$ urine samples (Table 2).

As summarized in Table 2, the excretion of JCPyV among HIV-infected group was more common $(80.2 \%)$ with a significant difference compared with shedding in healthy group (53.8\%) $(P=0.001)$.

While the excretion of JC polyomavirus in male HIVinfected patients was more than in female patients, and greater in healthy females than in their male counterparts, no significant difference was observed in the shedding of JCPyV between males and females $(P=0.317)$.

To find the correlation between age and incidence of viral DNA, the two groups were organized into 4 age groups: 0-19, 20-39, 40-59, and over 60 years (Table 2). The investigation revealed that in HIV-infected patients, the frequency of viral shedding increased with age and was higher in the oldest age group, though no significant difference was observed $(P=0.015)$. However, in the healthy individuals, the prevalence of JCPyV lost the age-related pattern so, in the youngest group (0-19 years, $58.3 \%$ ) was more than in the two older groups (groups 2039 and 40-59 years). Note that the relationship between age and shedding of JCPyV had no significant difference $(P=0.320)$. In both groups, the viral shedding of JCPyV in the eldest group ( $>60$ year) was the highest among all age population groups $(100.0 \%$ in HIV-infected patients and $73.3 \%$ in healthy individuals). Overall, in all samples classified according to age population groups, the presence of $\mathrm{JCPyV}$ in the urine increased given the age group though no significant difference was traced $(P=0.229)$. 
Table 2 Excretion of JCPyV among HIV-infected patients and healthy individuals

\begin{tabular}{|c|c|c|c|c|c|c|c|c|c|}
\hline \multirow[b]{2}{*}{ Group } & \multicolumn{5}{|c|}{ JCPyV positive number/age groups (\%) } & \multicolumn{4}{|c|}{ JCPyV positive number/total number of individuals (\%) } \\
\hline & $0-19$ & $20-39$ & $40-59$ & $>60$ & $p$ value & female & male & $p$ value & total $*$ \\
\hline HIV-infected patients & $0 / 1(0.0)$ & $33 / 46(73.7)$ & $27 / 29(93.1)$ & $5 / 5(100)$ & 0.015 & $20 / 23(86.9)$ & $45 / 58(77)$ & 0.317 & $65 / 81(80.2)$ \\
\hline Healthy individuals & $7 / 12(58.3)$ & $12 / 27(44.4)$ & $13 / 26(50.0)$ & $11 / 15(73.3)$ & 0.320 & $26 / 50(52)$ & $17 / 30(56.6)$ & $"$ & $43 / 80(53.8)$ \\
\hline Total & $7 / 13(53.8)$ & $45 / 73(61.6)$ & $40 / 55(72.7)$ & $16 / 20(80.8)$ & 0.229 & $46 / 73(63)$ & $62 / 88(70.4)$ & $"$ & $108 / 161(67.1)$ \\
\hline
\end{tabular}

*Significant difference was observed in the excreting of JCPyV among HIV-infected patients compare with healthy individuals $(P=0.001)$

\section{Identification of JCPyV genotyping}

In order to detect the distribution of different types of JCPyV in urine samples of both HIV-infected patients and healthy group, 26 out of 108 positive samples were picked out randomly and subjected to multiple alignments after obtaining sequences. Analysis of nucleotide blast and phylogenetic tree constructed using maximum likelihood indicated that the most common genotype was type 3 , subtype A which is the most prevalent type in Africa. The other identified genotypes were 2, 4, and 7 (Table 3). Type $3 \mathrm{~A}$ was the most predominant type in the two groups of HIV-infected patients and healthy individuals. Notably, the other types of JCV $(2,4$, and 7$)$ were also identified among the HIV-infected patients. Neither type 1 nor type 6 was identified in this study (Fig. 1).

As seen in Table 4, this subtype is different with genotype $3 \mathrm{~A}$ in some typing sites like position 1654 that changed from $T$ (genotype 3 ) to $A$ (genotype 1 ) or in position 2311 that nucleotide substitution $\mathrm{T} \rightarrow \mathrm{A}$ was observed. This nucleotide substitutions were seen in other typing sites which were represented above.

\section{Discussion}

JCPyV is a member of the Polyomaviridae family infecting human in the late childhood without any symptom and then persists in the kidneys, bone marrow, and lymphoid tissues $[26,27]$. According to the seroepidemiological investigations, approximately $80 \%$ of human population is JCPyV

Table 3 Distribution of JCPyV genotypes from HIV-infected patients and healthy individuals

\begin{tabular}{llll}
\hline Genotypes & HIV-infected patients & Healthy individuals & Total \\
\hline 2D & $3 / 19(15.7 \%)$ & 0 & $3 / 26(11.5)$ \\
$3 \mathrm{~A}$ & $14 / 19(73.7 \%)$ & $7 / 7(100 \%)$ & $21 / 26(80.8 \%)$ \\
4 & $1 / 19(5.3 \%)$ & 0 & $1 / 26(3.8 \%)$ \\
7 & $1 / 19(5.3 \%)$ & 0 & $1 / 26(3.8 \%)$ \\
\hline
\end{tabular}

Type $3 \mathrm{~A}$ was the most common type in both groups followed by genotypes 2D, 4, and 7 only in HIV-infected group. JCPyV genotypes 1 and 6 were not detected in either of the two groups seropositive while only $40 \%$ of human population excretes JCPyV in their urine $[5,6]$.

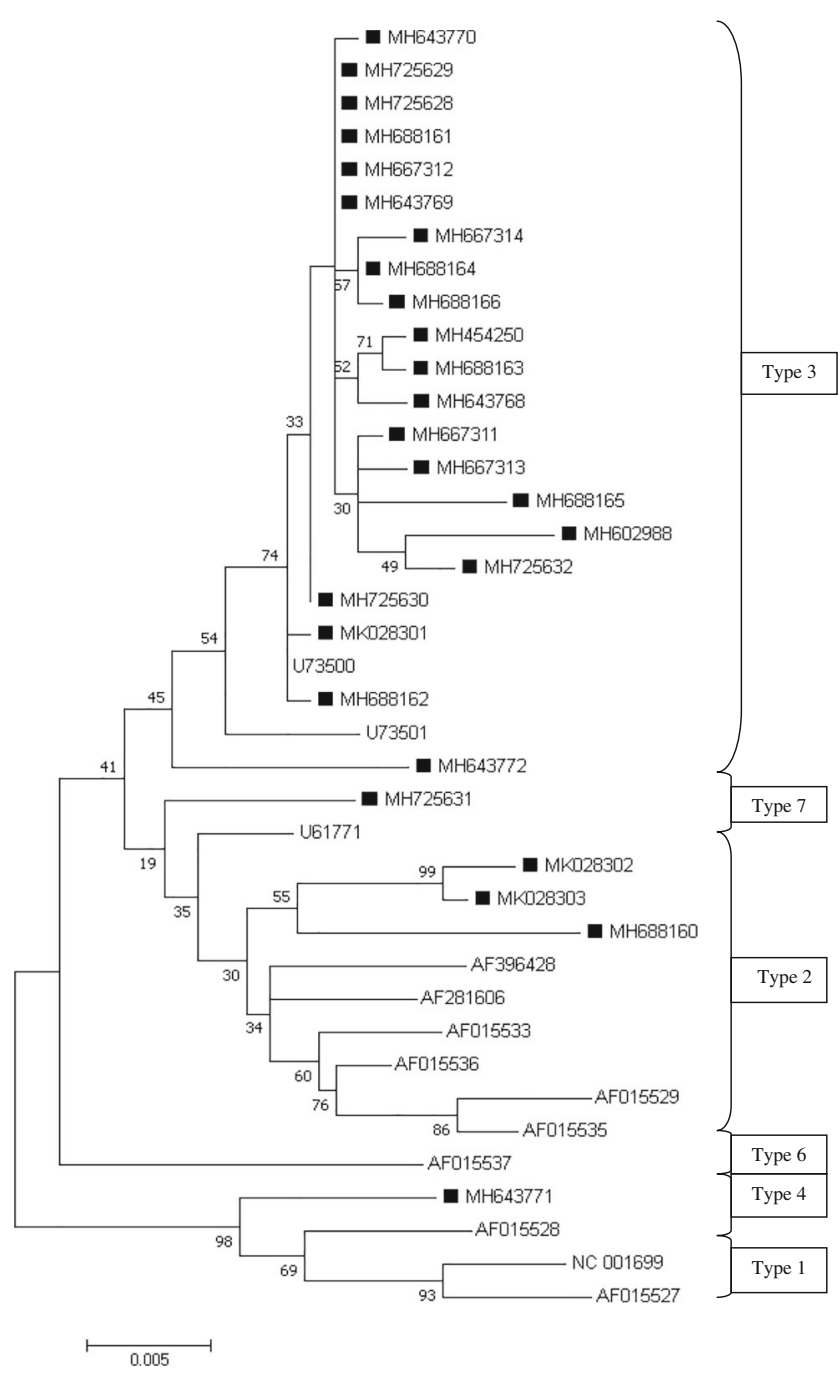

Fig. 1 Maximum likelihood phylogenetic tree of JCPyV VP1 region. Phylogenic analysis based on the VP1 coding sequences. Phylogenetic analysis of the JCPyV VP1 gene (1065 bp) was completed by PCR. The Clustal W method was used to align the sequences. The phylogenetic tree was built according to maximum likelihood under the Tamura Nei-model using MEGA 7. The scale bars demonstrate the frequency of nucleotide substitutions. The precision of the tree was assessed by 1000 bootstrap replicates. The isolations obtained in this study are shown in black squares (a). GenBank accession numbers of all sequences are presented in the tree 
Table 4 Genotype variants in the VP1 gene fragment

\begin{tabular}{|c|c|c|c|c|c|c|c|c|c|c|c|c|c|c|c|c|c|}
\hline Strain & Type & 1654 & 1753 & 1771 & 1786 & 1804 & 1843 & 1850 & 1869 & 1870 & 2311 & 2432 & 2435 & 2455 & 2482 & 2502 & Accession no \\
\hline Mad-1 & $1 \mathrm{~A}$ & $\mathbf{A}$ & $\mathbf{A}$ & C & G & $T$ & G & A & G & G & G & A & A & $\mathbf{A}$ & C & A & NC001699 \\
\hline 123 & 1B & A & A & $\mathrm{C}$ & G & $\mathrm{T}$ & $T$ & $G$ & G & G & $T$ & A & A & A & $\mathrm{C}$ & $G$ & AF015527 \\
\hline 224 & $2 \mathrm{~A}$ & $T$ & A & A & $T$ & $\mathrm{~T}$ & $T$ & A & G & A & $T$ & A & A & $G$ & $\mathrm{C}$ & $G$ & AF015529 \\
\hline 227 & $2 \mathrm{~B}$ & $T$ & A & $A$ & $T$ & $\mathrm{~T}$ & $T$ & $G$ & G & $A$ & $T$ & A & A & $G$ & $\mathrm{C}$ & $G$ & AF015533 \\
\hline 229 & $2 \mathrm{C}$ & $T$ & A & A & $T$ & $\mathrm{~T}$ & $T$ & $G$ & G & A & $T$ & A & A & $G$ & $\mathrm{C}$ & $G$ & AF015535 \\
\hline 230 & $2 \mathrm{D}$ & $T$ & A & A & $T$ & $\mathrm{~T}$ & $T$ & $G$ & G & A & $T$ & A & A & G & $\mathrm{C}$ & $G$ & AF015536 \\
\hline 234 & $2 \mathrm{E}$ & $T$ & A & $A$ & G & $\mathrm{T}$ & $T$ & A & G & A & $T$ & A & A & G & $\mathrm{C}$ & $G$ & AF281606 \\
\hline 308 & $3 \mathrm{~A}$ & $T$ & $T$ & A & $T$ & C & $T$ & A & C & A & $T$ & A & A & $G$ & $T$ & $G$ & U73500 \\
\hline SA296-02 & 3B & $T$ & $T$ & $A$ & G & $\mathrm{T}$ & $T$ & A & C & $A$ & $T$ & A & A & G & $T$ & $G$ & U73501 \\
\hline 402 & 4 & A & A & $C$ & G & $\mathrm{T}$ & G & A & $C$ & $A$ & $T$ & A & A & A & $\mathrm{C}$ & $G$ & AF015528 \\
\hline 601 & 6 & $T$ & A & A & G & $\mathrm{T}$ & $T$ & A & G & G & $T$ & A & A & $G$ & $\mathrm{C}$ & $G$ & AF015537 \\
\hline Tai-3 & 7 & $T$ & A & A & G & $\mathrm{T}$ & $T$ & A & G & $A$ & $T$ & A & A & $G$ & $\mathrm{C}$ & G & U61771 \\
\hline 805-B & 8 & $\mathrm{~T}$ & A & G & G & $\mathrm{T}$ & $\mathrm{T}$ & A & G & A & $\mathrm{T}$ & A & A & G & $\mathrm{C}$ & G & AF396428 \\
\hline $11 \mathrm{H}$ this study & $3 \mathrm{~A}$ & $\mathbf{A}$ & $\mathbf{A}$ & C & G & $\mathbf{T}$ & G & A & C & A & G & $\mathbf{A}$ & A & A & C & A & MH643772 \\
\hline
\end{tabular}

The comparison of isolated Ahvaz11h in the VP1 with other genotypes and subtypes of JCPyV. The different nucleotides with prototype Mad-1 are shown in italics. The similar nucleotides with strain Mad-1 which were identified in this study are shown in bold. The sequences used for comparison were provided by the National Center for Biotechnology (NCBI)

In Iran, there is little information about the prevalence and genotyping of JC polyomavirus and the relationship between the risk of PML and JCPyV infection. Therefore, this study was carried out to reveal the prevalence and genotyping of JCPyV in HIV-infected patients in comparison with healthy individuals in Ahvaz city in southwest of Iran.

Concerning all urine specimens, our findings revealed a total prevalence of JCPyV shedding of $67.1 \%$. Among HIVinfected patients, the prevalence of JCPyV excretion (80.2\%) was more than healthy individuals $(53.8 \%)$ which indicated a significant difference between case and control groups $(P=$ 0.001). While some previous studies reported that JCPyV excretion in urine would be not magnified by HIV infection [28, 29], Lednicky et al. showed a difference (not statistically meaningful) in urinary viral excretion between HIV-infected patients and HIV-uninfected volunteers [25]. Likewise, a study in an Irish population conducted by Schaffer et al. and a study carried out by Zanotta et al. in Northern Italy showed a significant difference in JCPyV shedding in urine between immunocompetent individuals and HIV-positive patients [3, 30]. These observations suggest that the impaired immune function system in HIV-infected patients may increase the replication of JCPyV in renal tissue, while receiving HAART treatment does not affect JCPyV excretion.

Regarding the preceding studies, the JC polyomavirus isolation rises with age $[4,6,22,31]$. The findings of this study indicated the age-related pattern of JCPyV excretion in HIVinfected patients $(P=0.015)$, but such a typical pattern was not observed in healthy group $(P=0.320)$.
JC polyomavirus is ubiquitous in human and with all JCPyV isolates belonging to a unique serotype [32]. Different genotypes of JCPyV are identified worldwide and are linked with specific geographic regions and human migration [7]. In the present research, the most dominant genotype in the two groups was genotype 3A $(80.8 \%)$, followed by genotypes $2 \mathrm{D}$ $(11.5 \%), 4(3.8 \%)$, and 7 (3.8\%), respectively. Neither genotype 1 nor 6 was identified in this study. Genotype 3A (Af2) is an African genotypes which is also found in the western and southern parts of Asia such as Turkey, Saudi Arabia, and India as reported by Sugimoto et al. [32,33]. This research confirms previous findings concerning this issue.

Genotypes 3A obtained in this investigation were very similar to isolate QLD-01 from Australia [19] except for positions 2311 and 2502. Also, some of the isolates obtained in this study were similar to isolate 308 from Tanzania (Table 5). The cycle sequencing results and comparison of sequences retrieved from GenBank, isolate "Ahvaz 11H" showed different nucleotides at some positions (Table 4). These differences revealed a potential for a new subtype. This sequence showed 99\% similarity with genotype 3A, but at some positions nucleotides were like prototype Mad-1 and differed from other genotypes 3. Furthermore, the $\mathrm{G} \rightarrow$ A substitution at positions 2432 and 2435 led to amino acid changes: Glutamine to lysine at positions 324 and 325 though changes in these sites are not type specific.

In conclusion, the results of the present study indicated that the JCPyV excretion was significantly higher among HIVinfected patients than in healthy individuals, while the prevalence of viral DNA between males and females was not 
Table 5 Comparison of nucleotides at positions 2311 and 2502 in genotypes 3A in this study with strains Mad-1 (NC001699), 308 (U73500), and QLD-01 (HG764413)

\begin{tabular}{|c|c|c|}
\hline Strains & 2311 & 2502 \\
\hline Mad-1(1A) (NC001699) & G & A \\
\hline $308(3 \mathrm{~A})(\mathrm{U} 73500)$ & $T$ & $G$ \\
\hline QLD-01(3A) (HG764413) & G & A \\
\hline MH454250 & G & A \\
\hline MH602988 & G & $G$ \\
\hline MH643768 & G & A \\
\hline MH643768 & G & A \\
\hline MH643770 & G & A \\
\hline MH643772 & G & A \\
\hline MH667311 & G & A \\
\hline MH667312 & G & A \\
\hline MH667313 & G & A \\
\hline MH667314 & G & $\mathrm{A}$ \\
\hline MH688161 & G & A \\
\hline MH688162 & G & $G$ \\
\hline MH688163 & G & $\mathrm{A}$ \\
\hline MH688162 & $T$ & A \\
\hline MH688165 & G & A \\
\hline MH688166 & G & A \\
\hline MH725628 & G & $\mathrm{A}$ \\
\hline MH725629 & G & A \\
\hline MK028301 & $T$ & A \\
\hline MH725630 & $\mathrm{G}$ & $G$ \\
\hline MH725632 & G & $G$ \\
\hline
\end{tabular}

Differences/similarities between the isolations obtained in this study with/ to isolates Mad-1, 308, and QLD-01. Different nucleotides with isolate QLD-01 are shown in italics. All genotypes of this study presented in Table 5 belong to genotype $3 \mathrm{~A}$

different as among the age-related groups. Moreover, our findings revealed that the predominant genotype in southwest of Iran was genotype $3 \mathrm{~A}$, followed by genotypes $2 \mathrm{D}, 4$, and 7 whereas neither genotype 1 nor 6 was found.

Acknowledgments This work was registered with registration number B97042 and supported by the Ahvaz Jundishapur University of Medical Sciences.

Authors' contributions Study concept and design: Manoochehr Makvandi. Acquisition of data: Roya Pirmoradi. Anlysis and interpretation of data: Manoochehr Makvandi and Roya Pirmoradi. Drafting of manuscript: Roya Pirmoradi and Somayeh Biparva Haghighi. Critical revision of the manuscript for important intellectual concept: Manochehr Makvandi. Statistical analysis: Maryam Dastoorpoor and Roya Pirmoradi. Administrative, technical, and material support: Roya Pirmoradi, Mohammad Karimi Babaahmadi, Nastaren Khodadad, and Maryam Tabasi. Supervision: Manoocher Makvandi and Hayat Mombeini.

\section{Compliance with ethical standards}

Conflict of interest The authors declare that they have no conflict of interest.

Ethnic consent The project was approved with approval number NO: B-97042 and ethical code of IR.AJUMS.REC.1397.446 by ethnic committee of Ahvaz Jundishapur University of Medical Sciences, Ahvaz, Iran.

Ethical issues Prior to the sampling procedures, informed consent was obtained from all participants or parents (in case of minor participants).

\section{References}

1. Hori R, Murai Y, Tsuneyama K, Abdel-Aziz HO, Nomoto K, Takahashi H, Cheng CM, Kuchina T, Harman BV, Takano Y (2005) Detection of JC virus DNA sequences in colorectal cancers in Japan. Virchows Arch 447(4):723-730

2. Van Loy T, Thys K, Tritsmans L, Stuyver LJ (2013) Quasispecies analysis of JC virus DNA present in urine of healthy subjects. PloS One 8(8):e70950. https://doi.org/10.1371/journal.pone.0070950

3. Zanotta N, Delbue S, Rossi T, Pelos G, D'Agaro P, Monasta L, Ferrante P, Comar M (2013) Molecular epidemiology of JCV genotypes in patients and healthy subjects from Northern Italy. J Med Virol 85(7):1286-1292. https://doi.org/10.1002/jmv.23585

4. Delbue S, Ferraresso M, Ghio L, Carloni C, Carluccio S, Belingheri M, Edefonti A, Ferrante P (2013) A review on JC virus infection in kidney transplant recipients. Clin Dev Immunol 2013:926391. https://doi.org/10.1155/922013/926391

5. Kmieciak D, Debicki S, Trzeciak WH (2008) Occurrence rate and genotype distribution of the JC virus (JCV) in a sample from the Polish population. J Med Virol 80(6):1079-1083. https://doi.org/ 10.1002/jmv.21153

6. Ferenczy MW, Marshall LJ, Nelson CD, Atwood WJ, Nath A, Khalili K, Major EO (2012) Molecular biology, epidemiology, and pathogenesis of progressive multifocal leukoencephalopathy, the JC virus-induced demyelinating disease of the human brain. Clin Microbiol Rev 25(3):471-506

7. Stolt A, Sasnauskas K, Koskela P, Lehtinen M, Dillner J (2003) Seroepidemiology of the human polyomaviruses. J Gen Virol 84(Pt 6):1499-1504. https://doi.org/10.1099/vir.1490.18842-18840

8. Guo J, Kitamura T, Ebihara H, Sugimoto C, Kunitake T, Takehisa J, Na YQ, Al-Ahdal MN, Hallin A, Kawabe K (1996) Geographical distribution of the human polyomavirus JC virus types A and B and isolation of a new type from Ghana. J Gen Virol 77(5):919-927

9. Yogo Y, Iida T, Taguchi F, Kitamura T, Aso Y (1991) Typing of human polyomavirus $\mathrm{JC}$ virus on the basis of restriction fragment length polymorphisms. J Clin Microbiol 29(10):2130-2138

10. Agostini HT, Jobes DV, Stoner GL (2001) Molecular evolution and epidemiology of JC virus. In: Khalili K, Stoner G (eds) Human polyomaviruses: molecular and clinical perspectives. Willy, New York, pp 491-526

11. Agostini H, Ryschkewitsch C, Mory R, Singer E, STONER GL (1997) JC virus (JCV) genotypes in brain tissue from patients with progressive multifocal leukoencephalopathy (PML) and in urine from controls without PML: increased frequency of JCV type 2 in PML. JID 176:1-8

12. Dubois V, Moret H, Lafon M-E, Brodard V, Icart J, Ruffault A, Guist'hau O, Buffet-Janvresse C, Abbed K, Dussaix E, Ingrand D (2001) JC virus genotypes in France: molecular epidemiology and potential significance for progressive multifocal leukoencephalopathy. JID 183:213-217 
13. Karalic D, Lazarevic I, Cupic M, Jovanovic T (2012) The prevalence of human polyomaviruses in urine samples of immunocompetent individuals in the Serbian population. Arch Biol Sci 64(4): 1383-1388. https://doi.org/10.2298/abs1204383k

14. Boothpur R, Brennan DC (2010) Human polyoma viruses and disease with emphasis on clinical BK and JC. J Clin Virol 47(4):306312

15. Jeong BH, Lee KH, Choi EK, Kim K, Kim YS (2004) Genotyping of the JC virus in urine samples of healthy Korean individuals. J Med Virol 72(2):281-289. https://doi.org/10.1002/jmv.10568

16. Venter M, Smit SB, Leman P, Swanepoel R (2004) Phylogenetic evidence of widespread distribution of genotype $3 \mathrm{JC}$ virus in Africa and identification of a type 7 isolate in an African AIDS patient. J Gen Virol 85(Pt 8):2215-2219

17. Shackelton LA, Rambaut A, Pybus OG, Holmes EC (2006) JC virus evolution and its association with human populations. J Virol 80(20):9928-9933. https://doi.org/10.1128/JVI.00441-00406

18. Takahashi K, Sekizuka T, Fukumoto H, Nakamichi K, Suzuki T, Sato Y, Hasegawa H, Kuroda M, Katano H (2017) Deep-sequence identification and role in virus replication of a JC virus quasispecies in patients with progressive multifocal leukoencephalopathy. $\mathrm{J}$ Virol 91(1):DOI: https://doi.org/10.1128/JVI.01335-01316

19. Bialasiewicz S, Hart G, Oliver K, Agnihotri SP, Koralnik IJ, Viscidi R, Nissen MD, Sloots TP, Burke MT, Isbel NM et al (2017) A difficult decision: atypical JC polyomavirus encephalopathy in a kidney transplant recipient. Transplantation 101(6):1461-1467. https://doi.org/10.1097/TP.0000000000001275

20. Reid CE, Li H, Sur G, Carmillo P, Bushnell S, Tizard R, McAuliffe M, Tonkin C, Simon K, Goelz S et al (2011) Sequencing and analysis of JC virus DNA from natalizumab-treated PML patients. JID 204(2):237-244. https://doi.org/10.1093/infdis/jir1256

21. Chen S, Tan IJK (2010) Progressive multifocal leukoencephalopathy and other disorders caused by JC virus: clinical features and pathogenesis. Lancet Neurol 9:425-437

22. Iannetta M, Bellizzi A, Menzo S, Anzivino E, D'Abramo A, Oliva A, D'Agostino C, d'Ettorre G, Pietropaolo V, Vullo V et al (2013) HIV-associated progressive multifocal leukoencephalopathy: longitudinal study of $\mathrm{JC}$ virus non-coding control region rearrangements and host immunity. J Neurovirol 19:274-279. https://doi.org/10. 1007/s13365-13013-10167-13369

23. Tavazzi E, White MK, Khalili K (2012) Progressive multifocal leukoencephalopathy: clinical and molecular aspects. Rev Med Virol 22(1):18-32

24. Wollebo HS, White MK, Gordon J, Berger JR, Khalili K (2015) Persistence and pathogenesis of the neurotropic polyomavirus JC. Ann Neurol 77(4):560-570
25. Lednicky JA, Vilchez RA, Keitel WA, Visnegarwala F, White ZS, Kozinetz CA, Lewis DE, Butel JS (2003) Polyomavirus JCV excretion and genotype analysis in HIV-infected patients receiving highly active antiretroviral therapy. Aids 17(6):801-807. https:// doi.org/10.1097/1001.aids.0000060327.0000012269. a0000060328

26. Behzad-Behbahani A, Klapper PE, Vallely PJ, Cleator GM, Khoo SH (2004) Detection of BK virus and JC virus DNA in urine samples from immunocompromised (HIV-infected) and immunocompetent (HIV-non-infected) patients using polymerase chain reaction and microplate hybridisation. Clin Diagn Virol 29(4):224-229. https://doi.org/10.1016/s1386-6532(1003)00155-00150

27. Zheng H-Y, Takasaka T, Ohno N, Sugimoto C, Kitamura T, Yogo Y (2007) Human dispersals based on a global phylogenetic analysis of JC virus isolates of genotype B1-b. Anthropol Sci 115(2):83-89. https://doi.org/10.1537/ase.061017

28. Markowitz R, Thompson H, Mueller J, Cohen J, WS D (1993) Incidence of BK virus and JC virus viruria in human immunodeficiency virus-infected and -uninfected subjects. JID 167:13-20

29. Sundsfjord A, Flaegstad T, Fie R, Spein A, Pedersen M, Permin H, Julsrud J, Traavik T (1994) BK and JC viruses in human immunodeficiency virus type 1-infected persons: prevalence, excretion, viremia, and viral regulatory regions. JID 169:485-490

30. Schaffer K, Sheehy N, Coughlan S, Bergin C, Hall WW (2006) JC virus in the Irish population: significant increase of genotype 2 in immunocompromised individuals. J Neurovirol 12(1):39-46. https://doi.org/10.1080/13550280600614965

31. Takasaka T, Miranda JJ, Sugimoto C, Paraguison R, Zheng H-Y, Kitamura T, Yogo Y (2004) Genotypes of JC virus in Southeast Asia and the western Pacific: implications for human migrations from Asia to the Pacific. Anthropol Sci 112(1):53-59. https://doi. org/10.1537/ase.00086

32. Sugimoto C, Kitamura T, GUO J, Al-Ahdal MN, Hchelkunov SN, Otova B, Ondrejka P, Chollet J-Y, El-Safi S (1997) Typing of urinary JC virus DNA offers a novel means of tracing human migrations. Proc Natl Acad Sci 94:9191-9196

33. Yogo Y, Sugimoto C, Zheng HY, Ikegaya H, Takasaka T, Kitamura $\mathrm{T}$ (2004) JC virus genotyping offers a new paradigm in the study of human populations. Rev Med Virol 14(3):179-191

Publisher's note Springer Nature remains neutral with regard to jurisdictional claims in published maps and institutional affiliations. 